\title{
More than a Vacation: Short-Term Study Abroad as a Critically Reflective, Transformative Learning Experience
}

\author{
Lane Perry ${ }^{1}$, Lee Stoner ${ }^{2}$, Michael Tarrant ${ }^{3}$ \\ ${ }^{1}$ Educational Studies and Human Development, University of Canterbury, Christchurch, New Zealand \\ ${ }^{2}$ School of Sport and Exercise, Massey University, Wellington, New Zealand \\ ${ }^{3}$ Warnell School of Forestry and Natural Resources, University of Georgia, Athens, USA \\ Email: lane.perry@canterbury.ac.nz, l.stoner@massey.ac.nz, tarrant@uga.edu
}

Received June 22 ${ }^{\text {nd }}, 2012$; revised July 20 ${ }^{\text {th }}, 2012$; accepted August $5^{\text {th }}, 2012$

\begin{abstract}
Over the past decade there have been increasing calls to develop the capacity of United States students to think and act globally (Stearns, 2009). One method of encouraging the civic of global citizenship is through study abroad (Tarrant, 2010). However, the educational value and legitimacy of study abroad, in particular short-term programs, has been questioned (Tarrant \& Lyons, 2012). This review and commentary will endeavor to support short-term study abroad as a creative, engaging, and effective educative practice. Building on a proposed theoretical framework grounding investigations focused on study abroad and global citizenship (Tarrant, 2010), a review of literature will examine Dewey's $(1933,1938)$ conceptualization of educative experiences as necessary and valuable components for a learner, and Mezirow's (1991) transformative learning theory (TLT) in connection with the fundamental role that critical reflection serves in both established perspectives of learning. Of particular concern is establishing the alignment between studies abroad, the philosophical and theoretical underpinnings of TLT, and the perspective development of learners in connection with global citizenship. By intentionally connecting Dewey and Mezirow's conceptualizations of learning with Tarrant's conceptual framework for studies abroad, a call for further research focusing on the experiences and perspectives of students within short-term study abroad environments can be made.
\end{abstract}

Keywords: Educative Experiences; Transformative Learning; Critical Reflection; Higher Education

\section{Introduction}

Over the past decade there have been increasing calls to develop the capacity of United States students to think and act globally (Stearns, 2009). One method of encouraging the civic of global citizenship is through study abroad (Tarrant, 2010). Growth has gone from $\sim 75,000$ students in 1990 to $\sim 270,000$ today. Of this total, the fastest growing area has been short-term programs of two months or less. Currently, $57 \%$ of all US students abroad engage in short-term programs, in part because they can be taken during the summer, often include a study tour, and do not impact on a students' academic schedule of classes during the regular Fall and Spring semesters. (Institute of International Education, 2011). However, the educational value and legitimacy of study abroad, in particular short-term programs, has been questioned (Tarrant \& Lyons, 2012). The aim of this short commentary is to note that while further research is still required, for short-term study abroad to be fully identified as a catalyst for developing a global citizenry, we recognize that when academic content and pedagogical delivery are considered the support and case for short-term study abroad to be identified as a creative, engaging, and effective educative practice becomes clearer. It is our assumption that this can best be accomplished by viewing short-term study abroad as a source of transformative learning through concrete, real-world experiences and critical reflection. This is particularly relevant when overcoming the "just do it" analogy that sometimes influences the ideology underpinning study abroad programs (Tarrant \& Lyons, 2012).

\section{Analytical Framework}

Building on a proposed theoretical framework grounding investigations focused on study abroad and global citizenship, a review of literature will examine Dewey's $(1933,1938)$ conceptualization of educative experiences as necessary and valuable components for a learner, and Mezirow's (1991) transformative learning theory (TLT) in connection with the fundamental role that critical reflection serves in both established perspectives of learning. Once the connection between Dewey's educative experiences and Mezirow's TLT is clarified by the role of critical reflection, the relevance of these underpinnings to Tarrant's (2010) conceptual framework for studies abroad in nurturing global citizenship will be explored. Of particular concern is establishing the alignment between studies abroad, the philosophical and theoretical underpinnings of TLT, and the perspective development of learners in connection with global citizenship.

\section{Dewey on Educative Experiences and Critical Reflection}

In Experience and Education Dewey (1938) identified the principles of continuity and interaction. With the principle of continuity, he sought to reference the past, present, and future experiences of a learner as a means to the educative process, and not only as ends. He also identified the importance of the transaction or situation that takes place among individuals and 
their environment, with the principle of interaction. This perspective is best summed up as follows: "just as no man lives or dies to himself, so no experience lives and dies to itself” (Dewey, 1938: p. 27). The previous experiences, situations, and interactions of learners today will continually resound in their present constructions of knowledge and future reconstructions, decisions, and actions based on that knowledge. Recognizing this, Dewey (1938: p. 25) specifically stated, "that amid all uncertainties there is one permanent frame of reference: namely, the organic connection between education and personal experience.” A learner's personal experiences are but one side of the coin. Those experiences, in connection with the other side-formalized education, can provide the environment and opportunity to develop the skills to critically analyze and reflect upon the bigger questions that can arise from within experiential education methodologies (e.g., service-learning, short-term study abroad, inquiry, place, or problem-based learning).

By building upon Dewey's (1933) suggestion that projects, which can be formal, teacher-facilitated experiences that are focused on real world problems, were the answer for producing knowledge and learning from a given experience, the following four criteria of an educative experience or project have been assumed:

1) Must generate interest;

2) Must be worthwhile intrinsically;

3) Must present problems that awaken new curiosity and create a demand for information;

4) Must cover a considerable time span and be capable of fostering development over time.

More specifically, Dewey believed that if a project or experience is truly educative, it can be very useful in presenting "typical problems to be solved by personal reflection and experimentation and by acquiring definite bodies of knowledge leading later to more specialized scientific knowledge" (Dewey, 1933: pp. 290-291). Perhaps the "typical problems to be solved" are found within atypical, different, or disorienting experiences had by learners. An example of an interesting environment where these types of "problems" may be evident is when learners are traveling and learning about different cultures, while becoming aware of perspectives other than those offered by their family, schooling, religion, workforce experiences, or their mainstream media. Additionally, it has been noted that Dewey recommends relating schooling and learning to life-real life/real experiences. Through experimentation, personal reflection, and the acquisition of definite bodies of knowledge, an educative project could lead to a more specialized scientific knowledge; thereby supporting and connecting curricular objectives with critical reflection and experiences that bring into question learners' typical or preprogrammed reactions to new and unusual environments or information. Moreover, projects or experiences that meet those four criteria become truly educative when they are linked by the "principles of continuity and interaction, the process of problematization and inquiry, and the phases of reflective thought” (Giles \& Eyler, 1994: p. 80).

The concept of constructing knowledge or basing future decisions and actions on that knowledge is hinged on the expectation that learners who have educative experiences will also be given the opportunity to critically reflect on those experiences. Supporting this expectation, Peterson (2002) determined that while experience may be one of the best teachers, it is never as valuable as when combined with and subjected to the critical analysis, reflection, and interpretation of a learner. According to Kember, Leung, Jones, Loke, McKay, Sinclair, Tse, Webb,
Wong, and Yeung (2000), Dewey is typically considered to be the originator of the idea of reflective thinking in connection with educative experiences. Furthermore, Kember et al. (2000) demonstrate the roots of Dewey in the theoretical underpinnings of their Questionnaire for Reflective Thinking (QRT). Dewey's work is of particular relevance to the development of two of the four scales that represent reflective thinking. Those scales are Reflection and Critical Reflection. These two scales are measured through participant responses to eight specific items. These items are based on participants' perceptions of their ability to actively question, carefully consider, challenge firmly held beliefs or ideas, implement processes that change their typical way of doing things, and to consider alternative ways of handling situations. All of these particular abilities (survey items) are related to Dewey's interpretation of reflection and measured by the QRT (Kember et al., 2000).

For example, Dewey (1933) considered reflection to be, "active, persistent and careful consideration of any belief or supposed form of knowledge in the light of the grounds that support it and the further conclusion to which it tends” (p. 9). He continued by identifying two certain sub-processes that are involved in all reflections. Dewey (1933) claims there must be a state of perplexity or hesitation that serves as the catalyst leading to active exploration or attempting to identify more information in order to confirm or contradict a learner's current or suggested belief. This particular assertion of Dewey will be further explored in context of Mezirow's disorientating dilemmas in the following section. In fact, without some acquaintance (read: past experience and prior knowledge) of a situation, "there is nothing upon which to draw in order to clarify it" (Dewey, 1910) and subsequently the urge to think and clarify the situation becomes unsuccessful.

This particular observation clearly presents the connection between past experiences and prior knowledge with reflection and meaning making. It is this process that can lead to learning. According to Moore (2005) learning is understood as "altering frames of reference through critical reflection of both habits of mind and points of view” (p. 82). Kolb (1984) identified learning as "the creation of knowledge and meaning [and] occurs through the active extension and grounding of ideas and experiences in the external world and through internal reflection about the attributes of these experiences and ideas" (1984: p. 53). The connection between experience and reflection is seemingly essential to learning. Past experiences carry with them a source for which to draw upon in future situations. This postulation is directly referring to the principles of continuity and interaction (Dewey, 1938). Furthermore, Dewey (1933) is aware that experience alone will not fully determine how we think. How we think is based on the process by which we test and assess a current situation based on previous experience within similar environments, our beliefs that have been shaped up to that exact moment, the knowledge we have access to and can apply, and the state of perplexity leading to critical reflection of the new experience. The sort of educative experiences that Dewey referenced are related to life, based on problems to be solved that awakened curiosity, of interest and intrinsically valuable to the learner, and brought with them a level of perplexity, doubt, or what Mezirow (1991) referred to as disorientating dilemmas.

\section{Mezirow on Transformative Learning Theory and Critical Reflection}

The concept of constructed knowledge based on experience 
and critical reflection upon experiences directly relates to Mezirow's (1991) transformative learning theory (TLT). Learning, in and of itself, is understood as adjusting frames of reference through critical reflection (Moore, 2005). Expanding this further, the concept of TLT is summarized by Smith and McKitrick (2010) as a learning process that is concerned with "get[ing] beyond" traditional or normative class purposes of knowledge attainment by embracing the perspective that learning can be more transformative when pursued in more "meaningful ways" (p. 50). While knowledge attainment may be transformative in its own right (Mezirow, 1991), it is when knowledge attainment is combined with active, hands-on experiential learning, that more "meaningful ways" may be uncovered.

The basis of TLT is founded on experiential activities or thought provoking scenarios and the opportunity for new perspectives to be developed through what Mezirow (1991) refers to as disorienting dilemmas. In this tenet, which serves as the departure point for TLT, resides Mezirow's assumption that learning can foster change or perspective transformation in the learner's self. From his 1975 inductive, qualitative study of 83 women from 12 specialized re-entry programs who were re-enrolling into university (1991: p. 168), Mezirow lists the following steps that can ultimately lead to a learner's transformation:

1) A disorienting dilemma;

2) Self-examination with feelings of guilt or shame;

3) A critical assessment of epistemic, sociocultural, or psychic assumptions;

4) Recognition that one's discontent and the process of transformation are shared and that others have negotiated a similar change;

5) Exploration of options for new roles, relationships, and actions;

6) Planning of a course of action;

7) Acquisition of knowledge and skills for implementing one's plans;

8) Provisional trying of new roles;

9) Building of competence and self-confidence in new roles and relationships;

10) A reintegration into one's life on the basis of conditions dictated by one's new perspective (Mezirow, 1991: pp. 168-169).

Addressing these phases originally discovered by Mezirow $(1975,1991)$, Taylor (1998 and 2007) confirmed the essentiality of "critical reflection, a disorienting dilemma as a catalyst for change, and many of the phases of the transformative process" (2007: p. 174). Of particular interest in Taylor's metaanalysis is Lange's (2004) study where she refers to disorientating dilemmas as "pedagogical entry points" (p. 183). These pedagogical entry points represent students' purposive engagement in their dilemmas, which may lead to a transformative experience. At these onramps leading to the freeway of learning, pedagogy can help students navigate their process of growth and transformation.

Beyond the previously listed phases, TLT can make use of pedagogies that align themselves with educative experiences and thought provoking scenarios. Mezirow (1991) explains that through the use of eye-opening discussions, books, or challenging experiences, it is pedagogically possible to foster an opportunity and environment conducive for students' perspective transformation. A process of perspective transformation can lead to a student becoming,

critically aware of how and why their assumptions have come to constrain the way they perceive, understand, and feel about their world; changing these structures of habitual expectation will make possible a more inclusive, discriminating, and integrative perspective; and, finally, making choices or otherwise acting upon these new understandings (Mezirow, 1991: p. 167).

Through the process which leads to a transformation of perspective, TLT focuses on the advancement and tuning of beliefs, attitudes, and emotional reactions based on the impact personal experiences have on individuals (Mezirow, 1991). Essentially, teaching practices that invoke a challenging problem to be solved in a way that may not align with the students' usual process of doing, thinking, or seeing, or experiences that are outside of their comfort zone (Perry, 2011), can bring about an opportunity for transformative learning. The process these students go through in adapting their actions, broadening their knowledge, and critically examining their perspectives can be influenced by experientially based pedagogy that focuses on critical reflection, and can lead to a transformative learning environment.

Fundamentally, TLT is concerned with not only the experience a learner has, but how they interpret and explain what happens. In turn this determines their "actions, their hopes, their contentment and emotional well-being, and their performance" (Mezirow, 1991: p. xiii). Furthermore, the how by which learners navigate the meaning and perspective making process is critical to how and what they learn, and subsequently should influence the way teachers facilitate learning environments. Again, this supports the postulation of Peterson (2002) that while experience may be one of the best teachers, it is never as valuable as when combined with and subjected to the critical analysis, reflection, and interpretation of a learner. Therefore, alignment with these perspectives from Mezirow and Dewey, in accordance with their illumination of critical reflection's value as an integral component in the experiential and transformative learning process, serves as a source for shifts in students' worldview. A conceptual framework that clearly addresses Peterson's (2002) connection between experience and a learner's critical reflection and interpretation is addressed in Tarrant (2010).

\section{A Conceptual Framework for Studies Abroad to Nurture Global Citizenship}

Imperative to understanding learning is recognizing how learners' beliefs, values, and experiences influence how meanings and perspectives are constructed. This particular point seems to be a primary concern of experiential educationalists. Whether using Dewey's (1933) educative experiences or project's criteria as a way of demonstrating learning or following Mezirow's (1991) ten phases of TLT, it is how learners use their own perspectives about the world, or field of study being pursued, to shape their subsequent understandings and actions through critical reflection. A particular conceptual framework that explored the role of studies abroad in nurturing global citizenship demonstrates the connection between learning and how beliefs and values can shape learning and behavior. Tarrant's (2010) conceptual framework maintains that students, "by engaging in an experientially structured study abroad program, a new worldview, predicated on a change in environmentally oriented values, norms, and behaviors, is nurtured and promoted" (p. 447). The promotion and nurturing of the shifts in students' worldviews seems to be rooted in the transformative nature of the experiences had while studying abroad and the critical reflection process that is concomitant to these types of student experiences. 
This fundamental process of analyzing, considering, reconsidering, and questioning experiences within context of students' experiences and personal perceptions is essential to the development of a "new worldview" that Tarrant (2010) references in his conceptual framework (see Figure 1).

In Tarrant's (2010) conceptualization of a framework for exploring the role of studies abroad education and global citizenship development, he posited a frame based on Stern's (2000) Values-Beliefs-Norm theory (VBN). In this, Tarrant identifies two components based on 1) an awareness/belief that specific environmental conditions threaten or have adverse consequences for the things the learner values and 2) an awareness/belief that the individual/learner can act to reduce the specific threat(s) (Stern, 2000 in Tarrant, 2010). These components and the extent to which an individual learner aligns with these two beliefs are critical to the conceptual framework Tarrant puts forth.

The recognition of critical reflection as an integral component of the conceptual framework offered by Tarrant (2010) is evident in Westheimer and Kahne's (2004) “citizen-type” and Dobson's (2003) "Earth Citizen”. For example, Westheimer and Kahne (2004) argue that a justice-oriented citizen is one who is concerned with asking questions about issues she or he sees in their community (local and global) and then acting upon the answers they find. This is in sharp contrast to a personally responsible citizen who is typically concerned with acting responsibly or volunteering in times of crisis. Interestingly, it seems that a clear difference between these two citizen types is found in the citizen's concern with or interest in critical reflection upon their observations and experiences. Justice-oriented citizens seem to be more concerned with asking the more complex questions versus accepting the simpler answers. By asking more complex questions, it is assumed that justice-oriented citizens are analyzing, considering, and reconsidering their perspectives and beliefs. This is primarily a function of critical thinking and reflection. Doing this may promote and nurture "change in environmentally oriented values, norms, and behaviors" (Tarrant, 2010: p. 447). This observation is demonstrated further by Dobson's view of an Earth Citizen. With an Earth Citizen there tends to be less emphasis on volunteerism as ends unto itself, and a greater emphasis placed on questioning what is observed or has come to be known and then this is acted upon in order to ameliorate the causes of observed injustices. Overall, the conceptual framework "proposes that values and worldviews act as filters for new information in the development and formation of congruent beliefs and attitudes which in turn predispose behavioral intentions and ultimately proenvironmental behaviors (Tarrant \& Cordell, 1997, 2002)” (Tarrant, 2010).
The outcomes of study abroad experiences, particularly those that are short-term in design, student's previous experiences with the course material, the destination, and travel in general can have an influence on the potential shift in a student's worldview. McKeown (2009) recognized the profound change in students' values when experiencing a new social environment that called into question their internal beliefs (see Tarrant, 2010) and referred to this as the first-time effect. This phenomenon has also been recognized in other learning environments where experientially based pedagogy (service-learning, problem-based learning) has been utilized (Perry, 2011; Perry, O’Steen, \& Cammock, in press). Valuable to the student experience and the likelihood of a shift in worldview are the following: faculty-student engagement, experiential learning opportunities, dialogue and group discussions focused on students' experiences, and reflection assignments connected to experiences and readings.

Within study abroad experiences, exposure to new places, cultures, and learning environments where a students' preconceived and established notions and beliefs are tested, may act as the catalyst or impetus for bring forth a transformative experience. Of particular importance is the creation of moments of critical reflection and discussion. In these types of environments, exposed to realties that are outside their previous understanding, the learner may discover a need to acquire new perspectives in order to gain a more complete understanding. A deeper, more sincere understanding of reality is the value in combining experiences with critical analysis and reflection. In order to determine the applicability of Tarrant's (2010) conceptual framework a sort of call to arms has been made. The "next step" is for empirical testing of the framework through quantitative and qualitative methods. The focus is on identifying the relevance of this conceptual framework for describing learning outcomes of study abroad and the learners' experiences as examples of sustained transformative learning.

\section{Conclusion and Personal Reflection}

Short-term study abroad could serve as a vehicle for fostering transformative learning environments where new experiences and perspectives may be developed. Most salient is the postulation that when coupled with an adequate pedagogical framework, short-term study abroad could serve as an educative opportunity for fostering transformative learning environments where new experiences and perspective may be developed. The critical moment where learners have engaged with something novel, whether it is physical or psychological, is when reflection and critical reflection become imperative to the learning

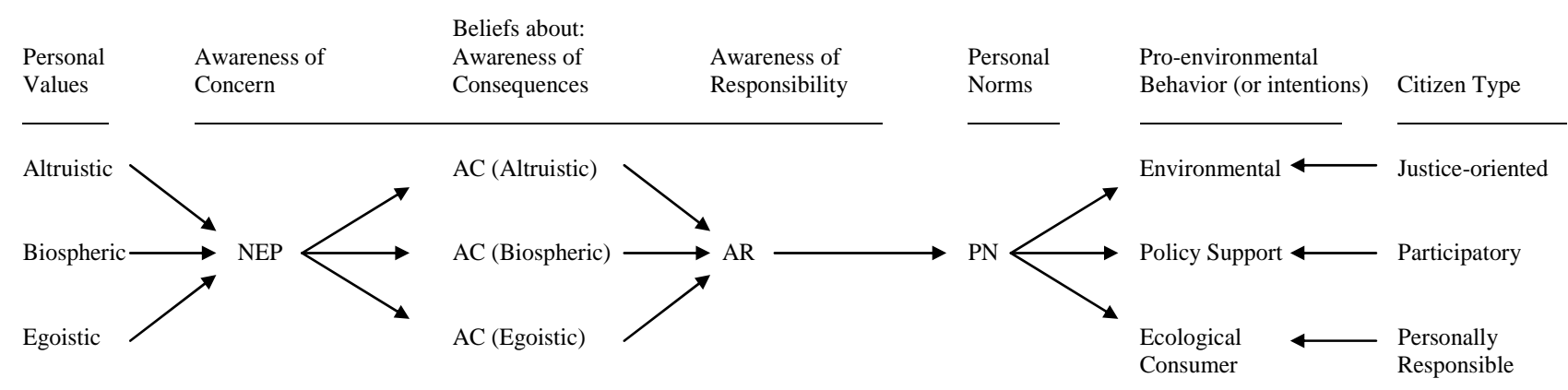

Figure 1.

Adapted value-beliefs-norms theory of global citizenship. 
process. Though it should be noted that prior to the exposure to something novel, abstract conceptualization can have occurred. Meaning, preparation for future experiences related to a student's involvement in a course is also valuable to their learning. These connections between experience and reflection, content and experience, and reflection and content are ones that have long been theoretically (Kolb, 1984; Dewey, 1938; Dewey 1933) and practically (Perry, 2011) established. By intentionally connecting Dewey and Mezirow's conceptualizations of learning with Tarrant's conceptual framework for studies abroad, a call for further research focusing on the experiences and perspectives of students within short-term study abroad environments can be made.

From this commentary I am reminded of a situation I recently experienced. I went to sleep, like any other night before, only to awake the following morning with my right eye swollen shut. I called the doctor, arranged an appointment, and within one-hour was waiting for the physician's diagnosis - a simple eye infection. Now then, as I walked back to the parking lot where my wife was waiting to take me back home, I realized how unaware I was of the world around me. I was unaware of the world that existed to the right of my nose. My right peripheral was more or less blinded. This particular experience sparked an idea in my thinking on the topics of reflection and critical reflection and led me to this postulation on the subject: Reflection and critical reflection are processes that create opportunities to stop and think, question, and discuss what you have experienced, read, written, or thought; so that perhaps, when you "restart" or "go back" to your thinking or doing experiences, you may be more aware of the role you play and the influence you have in your world. Essentially, transformative learning, educative experiences, and critical reflection are about opening a learner's metaphoric eyes and enlightening their perspectives through thought provoking scenarios, self-reflection, and dialogue. With regard to formal education, this can be related to fostering a heightened sense of awareness in a learner's cognitive and affective peripheral. Considering short-term study abroad is on the rise, perhaps by framing it within these literatures it can become strengthened, supported, and shaped to practically expose learner's to the related teaching methods.

\section{REFERENCES}

Dewey, J. (1910). What is thought? How we think, a restatement of the relation of reflective thinking to the educative process. URL (last checked 15 January 2012).

http://www.brocku.ca/MeadProject/Dewey/Dewey_1910a/Dewey_191 0_a.html

Dewey, J. (1933). How we think, a restatement of the relation of reflective thinking to the educative process. Boston, New York: D. C. Heath.

Dewey, J. (1938). Experience and education. New York: Collier Books.

Dobson, A. (2003). Citizenship and the environment. Oxford: Oxford University Press. doi:10.1093/0199258449.001.0001

Education, I. o. i. (2011). Open doors 2011 fast facts. URL (last checked 14 November 2011).

http://www.iie.org/Who-We-Are/News-and-Events/Press-Center/Pre ss-Rleases/2011/ /media/Files/Corporate/Open-Doors/Fast-Facts/Fas t-Facts-2011.ashx

Giles, D., \& Eyler, J. (1994). The theoretical roots of service-learning in John Dewey: Toward a theory of service-learning. Michigan Journal of Community Service Learning, 1, 77-85.
Kember, D., Leung, D., Jones, A., Loke, A., McKay, J., Sinclair, K., Tse, H., Webb, C., Wong, F., Wong, M., \& Yueng, E. (2000). Development of a questionnaire to measure the level of reflective thinking. Assessment \& Evaluation in Higher Education, 25, 381-395. doi:10.1080/713611442

Kolb, D. (1984). Experiential learning: Experiences as the source of learning and development. Englewood Cliffs, NJ: Prentice Hall, Inc.

Lange, E. (2004). Transformative and restorative learning: A vita dialectic for sustainable societies. Journal of Sustainable Tourism, 11, 459-475.

McKeown, J. S. (2009). The first time effect: The impact of study abroad on college student intellectual development. Albany, NY: State University of New York Press.

Mezirow, J. (1975). Education for perspective transformation: Women's reentry programs in community colleges. New York: Columbia University.

Mezirow, J. (1991). Transformative dimensions of adult learning. San Francisco: Jossey-Bass.

Moore, J. (2005). Is higher education read for transformative learning? A question explored in the study of sustainability. Journal of Transformative Education, 3, 76-91. doi:10.1177/1541344604270862

Perry, L. (2011). A naturalistic inquiry of service-learning in New Zealand classrooms: Determining and illuminating the influence on student engagement. Ph.D. Thesis, Christchurch: University of Canterbury.

Perry, L., O’Steen, B., \& Cammock, P. (In Press). Ma te mahi e ako ai (learning by doing): The influence of service-learning on student engagement. In A. Honigsfeld, \& A. Cohan (Eds.), Breaking the mold of classroom organization and management: Innovative and successful practices of engagement, motivation, and student empowerment for 21st century schools (Vol. 4). Lanham, MD: Rowman and Littlefield Inc.

Peterson, C. (2002). Preparing engaged citizens: Three models of experiential education for social justice. Frontiers: The Interdisciplinary Journal of Study Abroad, 8, 165-206.

Smith, J., \& McKitrick, A. (2010). Facilitating transformation through education: Promoting teaching of social responsibility and civic education for democracy. In J. Keshen, B. Holland, \& B. Moely (Eds.), Research for what? Making engaged scholarship matter (pp. 47-70). Charlotte, NC: Information Age Publishing, Inc.

Stearns, P. N. (2009). Educating global citizens in colleges and universities: Challenges and opportunities. New York: Routledge.

Stern, P. C. (2000). Toward a coherent theory of environmentally significant behavior. Journal of Social Issues, 56, 407-424. doi:10.1111/0022-4537.00175

Tarrant, M. A. (2010). A conceptual framework for exploring the role of studies abroad in nurturing global citizenship. Journal of Studies in International Education, 14, 433-451. doi:10.1177/1028315309348737

Tarrant, M. A., \& Cordell, H. K. (1997). The effect of respondent characteristics on environmental attitude-behavior correspondence. Environmental Management, 30, 618-637.

Tarrant, M. A., \& Lyons, K. (2012). The effect of short-term educational travel programs on environmental citizenship. Environmental Education Research, 18, 403-416. doi:10.1080/13504622.2011.625113

Taylor, E. W. (1998). The theory and practice of transformative learning: A critical review information series no. 374. Columbus: ERIC Clearinghouse on Adult, Career, and Vocational Education, Center on Education and Training for Employment, College of Education, The Ohio State University.

Taylor, E. W. (2007). An update of transformative learning theory: A critical review of the empirical research (1999-2005). International Journal of Lifelong Education, 26, 173-191.

Westheimer, J., \& Kahne, J. (2004). Educating the "good" citizen: Political choices and pedagogical goals. URL (last checked 25 January 2012). www.apsnet.org 